\title{
Studies on Rhodopsin
}

\section{RETINYLIDENEMETHYLAMINE, AN INDICATOR YELLOW ANALOGUE*}

\author{
By G. A. J. PITT, F. D. COLLINS, R. A. MORTON ANd PAULINE STOK \\ Department of Biochemistry, The University of Liverpool
}

(Received 16 June 1954)

The action of light on rhodopsin (visual purple) produces a pigment named, by Lythgoe (1937), 'indicator yellow' because it changes colour from a very pale yellow $\left(\lambda_{\max } .365 \mathrm{~m} \mu\right.$.) in alkaline solution to a much deeper yellow $\left(\lambda_{\max .} 440 \mathrm{~m} \mu\right.$.) on addition of acid. (In this paper, the terms indicator yellow, vitamin $A$ and retinene will be used to mean indicator yellow ${ }_{1}$, vitamin $A_{1}$ and retinene $e_{1}$.) Collins \& Morton (1950) and Collins (1953) have offered evidence that indicator yellow is not merely an artifact (using the word artifact here to mean a secondary product having no place in a cycle occurring under physiological conditions); in their view indicator yellow is more truly a derivative of rhodopsin, and it is the first photodecomposition product detectable in water at room temperature. Proof of the chemical nature of indicator yellow should be relevant to the structure of the rhodopsin chromophore, a fundamental issue which has so far been approached only tentatively.

The visual pigments and their derivatives possess characteristic absorption spectra, but the amounts present in the retina are too small to permit their characterization by ordinary chemical means. Even if sufficient material were obtainable, it is doubtful if chemical investigations would throw much light on the nature of a compound such as rhodopsin or indicator yellow formed from retinene (molecular weight, 284) and a protein (opsin) with a molecular weight of about 40000 . The most promising approach is to prepare a substance spectroscopically similar, but not containing the large protein moiety.

The final product of the action of light on rhodopsin in vitro is retinene (vitamin A aldehyde). A close relationship between this and indicator yellow became evident when retinene was found to link with many substances containing amino groups, i.e. amines, amino acids and proteins, to give products spectroscopically similar to indicator yellow (Ball, Collins, Dalvi \& Morton, 1949). These

* No. 7 of this series: Collins, Green \& Morton (1954).

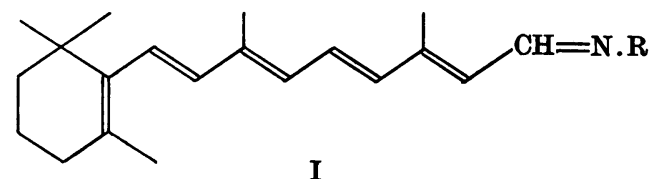

retinene-amino compounds clearly resemble the indicator yellow derived from rhodopsin and have been called 'indicator yellow analogues'.

Two possible structures have been put forward for these analogues in an alkaline medium: Ball et al. (1949) suggested they might be Schiff's bases (I), formed by the condensation of one molecule of retinene with one amino group of the amine or protein $\left(\mathbf{R} . \mathrm{NH}_{\mathbf{2}}\right)$.

Collins \& Morton (1950) tentatively proposed, for compounds other than those formed from aromatic amines, a tertiary amine structure in which two molecules of retinene joined with one amino group. They emphasized that proof of these suggested structures was lacking, as the substances were known only in solution.

The present paper describes the formation from retinene and methylamine of a crystalline indicator yellow analogue, which is shown to be a Schiff's base (I, $\mathrm{R}=\mathrm{CH}_{3}$ ). This structure could not be accepted without careful scrutiny because of the difficulty of explaining the shift of $\lambda_{\max }$ in acid solution. Evidence is now advanced that the displacement can be accounted for by the addition of a proton to the nitrogen atom to form a substituted ammonium salt (II, $\mathrm{R}=\mathrm{CH}_{3}, \mathrm{R}^{\prime}=\mathrm{H}$ ).

\section{RESULTS}

Retinene was condensed with methylamine and the product obtained as yellow crystals showing in solution the colour changes characteristic of natural indicator yellow and its synthetic analogues. Spectroscopic details are given in Table 1, and absorption curves in Figs. 1-3. Analytical results were: C, 84.7 ; H, 10.4; N, 4.9\%. Mol.wt. 290. Values calculated for the two previously proposed structures are: Schiff's base $\mathrm{C}_{21} \mathrm{H}_{31} \mathrm{~N}$ (Ball et al. 1949) $\mathrm{C}, 84 \cdot 9$; H, 10.4; N, 4.7\%. Mol.wt. 297. Tertiary amine $\mathrm{C}_{41} \mathrm{H}_{57} \mathrm{~N}$ (Collins \& Morton, 1950) $\mathrm{C}, 87.4 ; \mathrm{H}, 10 \cdot 1$; N, 2.5\%. Mol.wt. 563.

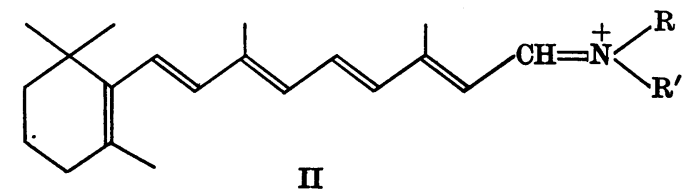


These results agree with the suggestion that the indicator yellow analogue formed from retinene and methylamine is a Schiff's base (I, $\mathrm{R}=\mathrm{CH}_{3}$ ), 3:7dimethyl - 9 - (2:6:6 - trimethylcyclohex - 1 - en - 1 - yl) nona-2:4:6:8-tetraenylidenemethylamine. We have given it the trivial name of retinylidenemethylamine. (In our proposed nomenclature for retinene derivatives-see p. 126-retinylidene is the name given to the $\mathrm{C}_{19} \mathrm{H}_{27} \mathrm{CH}=$ radical in $\mathrm{I}$.)

This structure contains the same chromophoric group as retinene oxime (I, $\mathrm{R}=\mathrm{OH}$ ), which should therefore have an absorption spectrum very similar to that of the indicator yellow analogue, if the Schiff's base structure is correct. Retinene oxime has been prepared by Farrar, Hamlet, Henbest \& Jones (1952) and in greater purity by Wald \& Brown (1953). Its molecular extinction coefficient has been reported only in polar solvents. Retinene oxime was therefore again prepared in order to compare its absorption spectrum and antimony trichloride colour reaction with those of retinylidenemethylamine. Details are given in Table 2. $\epsilon_{\max }$ in ethanol agrees well with that obtained by Wald \& Brown (1953). Fig. 2 shows the absorption spectra of retinene oxime and retinylidenemethylamine in light petroleum, a convenient non-polar

Table 1. Spectroscopic properties of retinylidenemethylamine

\begin{tabular}{lcc}
\multicolumn{1}{c}{ Solvent } & $\begin{array}{c}\lambda_{\max } \\
(\mathrm{m} \mu .)\end{array}$ & $\boldsymbol{\epsilon}_{\max .}$ \\
Light petroleum & $\mathbf{3 5 5}$ & $\mathbf{5 7 4 0 0}$ \\
*Water (0.5 M methylamine) & $\mathbf{3 6 5}$ & $\mathbf{4 9 3 0 0}$ \\
*Water (0.1 N-HCl) & $\mathbf{4 3 8}$ & $\mathbf{4 1 0 0 0}$ \\
$\mathrm{CHCl}_{\mathbf{3}}$ & $\mathbf{3 6 6}$ & $\mathbf{5 3 2 0 0}$ \\
$\mathrm{CHCl}_{\mathbf{3}}+\mathrm{HCl}$ & $\mathbf{4 6 6}$ & 50500 \\
$\mathrm{SbCl}_{3}$ colour reaction & $\mathbf{5 0 5}$ & $\mathbf{4 7 0 0 0}$
\end{tabular}

* Digitonin used as dispersing agent.

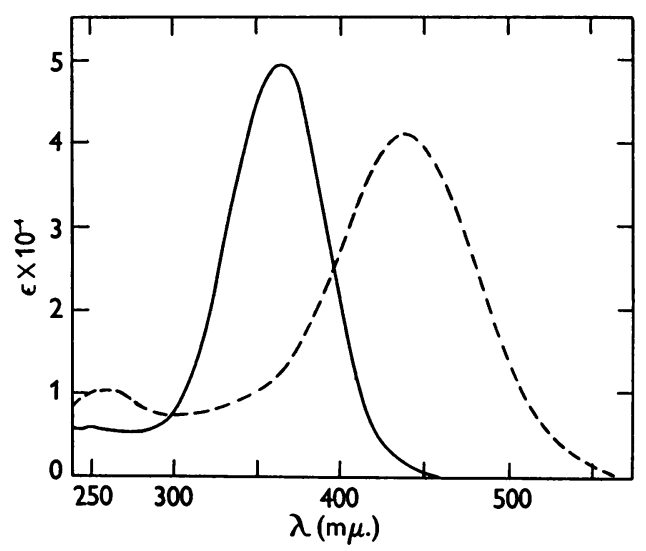

Fig. 1. Absorption spectrum of retinylidenemethylamine in water + methylamine, - - in water $+\mathrm{HCl},---$. (Dispersing agent-digitonin.) solvent for obtaining a just comparison. The nearly identical curves support the suggested Schiff's base structure of the indicator yellow analogue.

The antimony trichloride (Carr-Price) colour reactions of retinene oxime and retinylidenemethylamine differ somewhat in the position and intensity of the maximum but share features not found in the Carr-Price chromogens of other vitamin A derivatives. (1) The two compounds have colour-test maxima in the same spectral region, and at much shorter wavelengths (480 and $505 \mathrm{~m} \mu$.) than would be expected for compounds with six conjugated double bonds (cf. retinene, $664 \mathrm{~m} \mu$.; anhydrovitamin $A, 620 \mathrm{~m} \mu$.). (2) The molecular extinction coefficients in the colour test are of the same order and are unexpectedly low $(<50000)$ (cf. retinene, $\epsilon_{\max }, 108000$ (Hubbard, Gregerman \& Wald, 1953); anhydrovitamin $A, \epsilon_{\max }, 145000$ (Cama, Collins \& Morton, 1951)). (3) The colour-test absorption curves are broad with rounded peaks and half band-widths (distance in $\mathrm{m} \mu$. separating $\epsilon$ values at $\epsilon_{\max } / 2$ ) of approx. $110 \mathrm{~m} \mu$. The halfwidth for anhydrovitamin $A$ in antimony trichloride is $56 \mathrm{~m} \mu$. (calc. from Cama et al. 1951). (4) The chromogens are unusually stable. With retinyl-

Table 2. Spectroscopic properties of retinene oxime

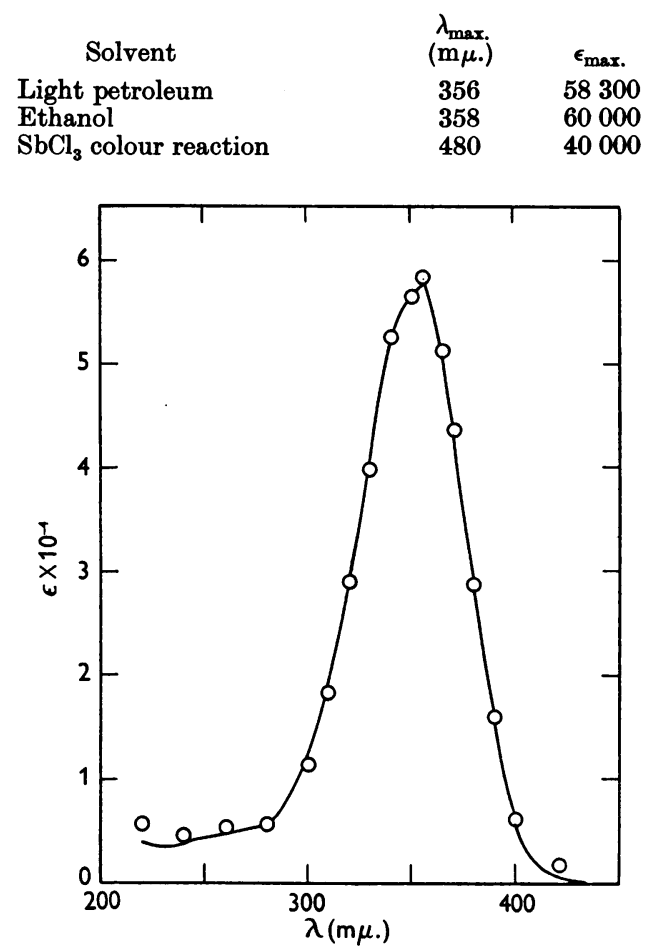

Fig. 2. Absorption spectrum in light petroleum of retinylidenemethylamine, mined for retinene oxime, $O$. 
idenemethylamine, the red colour fades very slowly and falls to half its original intensity after about a day; $\lambda_{\max }$ moves from its original position at $505 \mathrm{~m} \mu$. to $495 \mathrm{~m} \mu$. within a few min., but on standing for several $\mathrm{hr}$. it moves back to $508 \mathrm{~m} \mu$. With retinene oxime the colour fades more quickly, but even so persists for several $\mathrm{hr}$.

\section{Stability of retinylidenemethylamine}

Retinylidenemethylamine is extremely unstable. It is rapidly hydrolysed by mere traces of ethanol or water over a wide $\mathrm{pH}$ range, unless a great excess of methylamine is present (see Morton \& Pitt, 1955) and it is readily attacked by atmospheric oxygen. If a solution in light petroleum is left exposed to the air for $30 \mathrm{~min}$. at room temperature, an insoluble red breakdown product is deposited.

Owing to its instability, retinylidenemethylamine is difficult to purify by adsorption chromatography. It is broken down to retinene by strong adsorbents such as alumina, and although it is reasonably stable on weak adsorbents, such as calcium carbonate, these are not strong enough to separate it from accompanying impurities.

The preparation of pure retinylidenemethylamine is therefore a difficult task. The best method was found to be repeated crystallization from light petroleum at $-78^{\circ}$ in an atmosphere of nitrogen with exclusion of moisture. Without these precautions the product was impure and gave incorrect analytical results.

\section{The 'acid' form of retinylidenemethylamine}

On passing dry hydrogen chloride through a light petroleum solution of retinylidenemethylamine, a red material is precipitated (m.p. (decomp.) about $140^{\circ}$ ) which, when dissolved in chloroform, gives the absorption curve characteristic of the 'acid' form of retinylidenemethylamine. This is to be expected if a substituted ammonium salt is formed, as it will be insoluble in a non-polar solvent. Attempts to purify this crude product by crystallization failed, and analyses showed the presence of a variable excess of chloride and oxygen, presumably as a result of side reactions. The simplest explanation is that, in acid, retinylidenemethylamine forms a substituted ammonium salt (II, $\mathbf{R}=\mathbf{C H}_{3} \quad \mathbf{R}^{\prime}=\mathbf{H}$ ) as a typical Schiff's base. A possible alternative is a doubled molecule, the increase of $\lambda_{\max }$ being accounted for by the elongation of the chain of conjugated double bonds. Two lines of evidence, however, indicate that the simpler explanation is almost certainly correct.

The addition of a proton to retinylidenemethylamine introduces a positive charge into the nitrogen atom. This charge (which implies a local deficiency of electrons) could formally be localized at many positions along the polyene chain. At least seven distinct resonance forms can be written for the retinylidenemethylammonium ion compared with one main form for retinylidenemethylamine, resonance forms with low probability being neglected. Such increase in the degree of resonance would contribute to a shift in $\lambda_{\max }$ towards the visible.

So far as we know, it is not possible to find in the literature experimental evidence of such a big bathochromic shift associated unambiguously with a change of $\mathrm{a}-\mathrm{CH}=\mathrm{N}-$ grouping to $-\mathrm{CH}=\mathrm{NH}^{+}-$. To examine the validity of this idea, it is necessary to see if other similar compounds behave as retinylidenemethylamine.

Schiff's bases were formed in solution from methylamine with benzaldehyde, cinnamaldehyde, $\beta$-apo-12' -carotenal and $\beta$-apo-8'-carotenal. These apocarotenals (which were kindly provided by Mr E. R. Redfearn and Dr J. Glover) are aldehydes with polyene chains longer than that of retinene. On formation of the Schiff's bases in ethanolic solution by a method substantially that of Ball et al. (1949), a rise in extinction was observed. No marked change of $\lambda_{\max }$ was seen with benzaldehyde, but cinnamaldehyde showed a hypsochromic shift which was much more marked with the apocarotenals (Table 3). Similar effects are seen when retinene $\left(\lambda_{\max }\right.$ (ethanol), $383 \mathrm{~m} \mu . ; \epsilon_{\max .}$, 42900 (Wald \& Brown, 1953)) is converted into

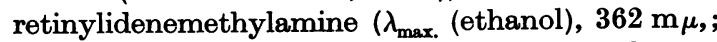
$\epsilon_{\text {max. }}, 55800$ ). The rise in extinction in each case shows that the Schiff's base of the aldehyde has been formed. Although benzaldehyde did not show the hypsochromic shift accompanying Schiff's base formation in the other aldehydes, such a shift is not always found with short conjugated chains. Indeed, when crotonaldehyde is converted into crotonylidene butylamine, although the extinction rises, $\lambda_{\max }$ moves slightly to longer wavelengths (Hausser, Kuhn, Smakula \& Hoffer, 1935; Barany, Braude \& Pianka, 1949).

On acidification, the solutions of all the Schiff's bases showed a bathochromic shift. Absorption maxima of these compounds are summarized and compared with the corresponding retinene derivatives in Table 3 .

\section{Table 3. $\lambda_{\max }$ of methylamine derivatives of aldehydes}

Solvent, ethanol.

\begin{tabular}{|c|c|c|c|}
\hline Aldehyde & $(m \mu)$. & In alkali & In acid \\
\hline Retinene & 383 & 362 & 439 \\
\hline Benzaldehyde & 246 & 245 & 273 \\
\hline Cinnamaldehyde & 286 & 282 & 324 \\
\hline B-apo-12'-Carotenal & 421 & 403 & 486 \\
\hline$\beta$-apo-8'-Carotenal & 459 & 444 & 520 \\
\hline
\end{tabular}

$\lambda_{\max }$ of Schiff's base $(\mathrm{m} \mu$.

B-apo-8'-Carotenal 
On acidifying, there was a fall in extinction of the apocarotenylidenemethylamine solutions similar to that seen with retinylidenemethylamine, but the extinction of the cinnamylidenemethylamine solution rose. Benzylidenemethylamine decomposed at an appreciable rate in acid, so that no accurate quantitative measurements were made. An increase in the degree of resonance (postulated as an explanation of the bathochromic shift) would be expected to cause a rise in extinction, as is seen with cinnamylidenemethylamine. It is somewhat unexpected that this is not found with the aliphatic Schiff's bases containing longer polyene chains, but the apocarotenylidenemethylamines parallel retinylidenemethylamine closely in this respect.

From these spectroscopic observations, it appears that the 'acid shift' found in retinylidenemethylamine is probably due to the conversion of the nitrogen atom to the quaternary state. To confirm this, another retinylideneammonium derivative of structure II was made.

Alkyl iodides are known to unite with Schiff's bases to give substituted ammonium iodides (Decker \& Becker, 1913). Methyl iodide was allowed to react with retinylidenemethylamine to form a product insoluble in light petroleum, but which dissolved in chloroform to give a broad curve (half-width $102 \mathrm{~m} \mu$.) with $\lambda_{\max } 485 \mathrm{~m} \mu$. (Fig. 3). This is presumably retinylidenedimethylammonium iodide (iodide of II, $\mathrm{R}=\mathrm{R}^{\prime}=\mathrm{CH}_{3}$ ). The material was stable in anhydrous ethanol and showed $\lambda_{\max }$. $455 \mathrm{~m} \mu$., but on dilution with water decomposed to give retinene. It also decomposed on making the ethanolic solution slightly alkaline $(0.001 \mathrm{M}-\mathrm{KOH})$.

Addition of antimony trichloride in chloroform gave a broad absorption band (half-width about $120 \mathrm{~m} \mu$.) with a maximum at $505 \mathrm{~m} \mu$., changing to

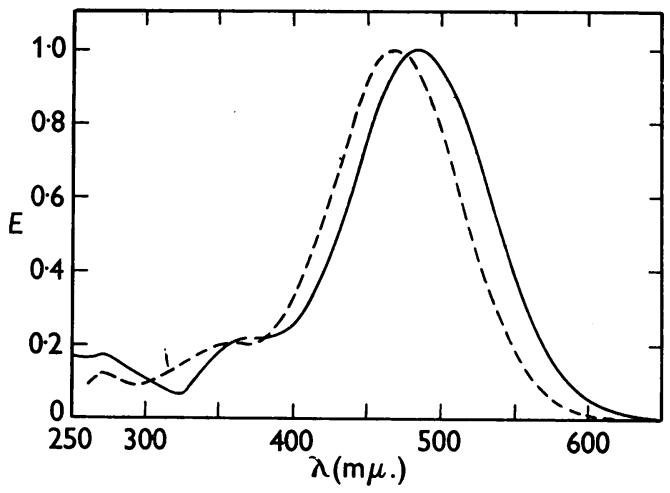

Fig. 3. Absorption spectra in chloroform: retinylidenemethylammonium chloride, - - -; retinylidenedimethylammonium iodide, $\longrightarrow$. Shown as $E_{\max }=1 \cdot 0$ (absolute value of $E_{\max }$ not known for retinylidenedimethylammonium iodide, but within $5 \%$ of that of retinylidenemethylammonium chloride).
$497 \mathrm{~m} \mu$. within a few minutes. The colour was relatively stable; after $7 \mathrm{hr}$., the intensity had dropped only to $73 \%$ of that originally developed, but $\lambda_{\max }$. had moved to $515 \mathrm{~m} \mu$. No other peak appeared at longer or shorter wavelengths.

Accurate determinations of the molecular extinction coefficients were not made owing to difficulty in purifying the material, but fairly reliable estimations of $\epsilon_{\max }$. in chloroform and of $\epsilon_{\max }$ of the antimony trichloride colour reaction showed them to be within $5 \%$ of those found with the acid form of retinylidenemethylamine.

The absorption spectrum in chloroform of retinylidenedimethylammonium iodide bears a strong resemblance to that of the acid form of retinylidenemethylamine (see Fig. 3). Both have relatively broad bands of approximately the same intensity, with an inflexion around $350-380 \mathrm{~m} \mu$. The difference of $19 \mathrm{~m} \mu .(466-485)$ in $\lambda_{\max }$ is presumably accounted for by the different substituents on the quaternary nitrogen atom; such an effect is commonly found among dyes (for a number of examples, see Dewar, 1949).

The strong resemblances in absorption spectrum and antimony trichloride colour reaction of retinylidenedimethylammonium iodide and the acid form of retinylidenemethylamine confirm that the shift with $\mathrm{pH}$ of $\lambda_{\max }$. of retinylidenemethylamine is due to the conversion of the nitrogen atom to the quaternary state.

Natural indicator yellow, derived directly from rhodopsin, therefore has structure $I(R=o p s i n)$ in alkali, and in acid, structure II $\left(R=\right.$ opsin, $\left.R^{\prime}=H\right)$.

\section{Retinylidenemethylamine in concentrated sulphuric acid}

Unstable coloured products, including those similar to their Carr-Price chromogens, are formed by vitamin $A$ and retinene when acted upon by concentrated sulphuric acid (Ball \& Morton, 1949). As antimony trichloride gives an unusual colour reaction with retinylidenemethylamine, it is of interest to know the effect of concentrated acid.

On dissolving retinylidenemethylamine in concentrated sulphuric acid $(98 \%, \mathrm{w} / \mathrm{w})$ a red-purple colour appeared $\left(\lambda_{\max .} 515-520 \mathrm{~m} \mu\right.$.). This faded very rapidly at room temperature, leaving a fairly stable peak about $430-435 \mathrm{~m} \mu$., with an extinction of about 0.3 of that initially observed at $520 \mathrm{~m} \mu$. No other peaks were found. Owing to the rapid fading of the 515-520 $\mathrm{m} \mu$. band, its extinction was not measured accurately, but it did not differ from that of the Carr-Price chromogen by more than $15 \%$.

Vitamin A and retinene in concentrated sulphuric acid give a number of peaks between 440 and $650 \mathrm{~m} \mu$. (Ball \& Morton, 1949). Retinylidenemethylamine in concentrated sulphuric acid, as in 
antimony trichloride solution, seems to be inhibited from forming chromogens with maxima on the long-wavelength side of $520 \mathrm{~m} \mu$.

\section{MATERIALS AND METHODS}

Antimony trichloride colour reaction. To a solution of the substance in $\mathrm{CHCl}_{3}$ was added a saturated solution of anhydrous $\mathrm{SbCl}_{3}$ in ethanol-free $\mathrm{CHCl}_{3}$ containing approx. $1 \%(v / v)$ acetic anhydride.

Absorption spectra were determined with a photoelectric spectrophotometer, except for some observations on the $\mathrm{H}_{2} \mathrm{SO}_{4}$ chromogen, made using a Hilger-Nutting visual instrument.

Analyses were by Weiler and Strauss, Oxford, and in some cases by the Department of Organic Chemistry, University of Liverpool, where the molecular-weight determination was made (Rast, camphene).

All work involving vitamin A, retinene or derivatives was carried out in red light or in very dim artificial light to avoid isomerization or photodestruction.

Light petroleum. The commercial product (b.p. 40-60 was used, except for absorption spectra, which were determined in light petroleum (b.p. $60-80^{\circ}$ ) free from aromatic hydrocarbons.

Chloroform. For the alkaline spectrum of retinylidenemethylamine, $\mathrm{CHCl}_{3}$ was first exposed to $\mathrm{NH}_{3}$ vapour to remove any traces of $\mathrm{HCl}$. For the acid spectrum, a little anhydrous $\mathrm{HCl}$ was bubbled through the $\mathrm{CHCl}_{3}$.

Aqueous solutions of retinylidenemethylamine. Digitonin $(1 \%, w / v)$ was used as dispersing agent. Solid retinylidenemethylamine was dissolved in a small volume $(<0.1 \mathrm{ml}$.) of ethanol containing excess methylamine to prevent hydrolysis (see Morton \& Pitt, 1955) and the digitonin solution added. For the alkaline spectrum, the digitonin solution contained methylamine $(0.5 \mathrm{M})$ and for the acid spectrum, $\mathrm{HCl}(0 \cdot 1 \mathrm{~N})$.

Retinene. This was prepared from synthetic all-transvitamin A (Hoffman-La Roche) by oxidation with $\mathrm{MnO}_{2}$ (Ball, Goodwin \& Morton, 1948). The crystalline material was used.

Retinylidenemethylamine. Retinene (1 g.) was dissolved in light petroleum $(50 \mathrm{ml}$.) and methylamine bubbled through. Anhydrous $\mathrm{Na}_{2} \mathrm{SO}_{4}(5 \mathrm{~g}$.) was added and the mixture left at room temperature. After $1 \mathrm{hr}$. the $\mathrm{SbCl}_{3}$ colour reaction of a small portion was examined. A band at $500 \mathrm{~m} \mu$. with no sign of a subsidiary band at $664 \mathrm{~m} \mu$. (due to retinene) confirmed that the reaction was complete. The solution was filtered through a sintered-glass funnel (porosity 4) and the filtrate dried at reduced pressure and room temperature. The residue crystallized at $-78^{\circ}$ from light petroleum as yellow needles. Repeated recrystallizations raised the m.p. to $7^{\circ}$ (uncorr.).

Retinene oxime. Hydroxylamine hydrochloride (20 g.) was dissolved in water $(30 \mathrm{ml}$.) and a $60 \%(\mathrm{w} / \mathrm{v})$ solution of $\mathrm{KOH}$ in water added to bring the $\mathrm{pH}$ to over $10 \cdot 5$. The mixture was poured on to a solution of retinene $(1 \cdot 7 \mathrm{~g}$.) in ethanol $\left(50 \mathrm{ml}\right.$.). After $10 \mathrm{~min} ., \lambda_{\max }$ of the solution had changed to $358 \mathrm{~m} \mu$., indicating substantially complete conversion into the oxime. The reaction mixture was diluted with water $(500 \mathrm{ml}$.) and extracted with ether. The extract was evaporated to dryness and the crude oxime recrystallized from methanol. M.p. 139-142 ${ }^{\circ}$ (uncorr.).

Methylamine derivatives of other aldehydes. To an ethanolic solution of the aldehyde (diluted to give a convenient reading in the spectrophotometer) were added 3 drops of a solution of methylamine $(33 \% \mathrm{w} / \mathrm{v})$ in ethanol. After $1 \mathrm{hr}$., the absorption curve of the Schiff's base was determined. Conc. HCl (4 drops) was added and the absorption curve examined again.

Retinylidenedimethylammonium iodide. Methyl iodide (5 ml.) was poured on to solid retinylidenemethylamine (102 mg.) and left at room temperature for $40 \mathrm{~min}$. The excess methyl iodide was removed by evaporation under reduced pressure at room temperature. The red residue was washed with light petroleum to remove any soluble material. Attempts to purify it by crystallization failed. The crude product had m.p. 140-145 ${ }^{\circ}$ (decomp.). (Found: C, 57.2; $\mathrm{H}, 7 \cdot 3 ; \mathrm{N}, 3 \cdot 2 ; \mathrm{I}, 31 \cdot 7 . \mathrm{C}_{22} \mathrm{H}_{34} \mathrm{NI}$ requires $\mathrm{C}, 60 \cdot 1 ; \mathrm{H}, 7 \cdot 8$; $\mathrm{N}, 3 \cdot 2 ; \mathrm{I}, 28.9 \%$.)

\section{DISCUSSION}

\section{Nomenclature}

Many workers are satisfied with the name vitamin $A_{1}$ for $\mathrm{C}_{20} \mathrm{H}_{29} \mathrm{OH}$ and vitamin $\mathrm{A}_{2}$ for $\mathrm{C}_{20} \mathrm{H}_{27} \mathrm{OH}$ and indeed there is much to be said for retaining these names in certain contexts. The same considerations apply to retinene $e_{1}$ and retinene $e_{2}$. The name 'axerophthol' for vitamin $\mathbf{A}_{1}$, suggested some years ago, has not won general acceptance.

It is difficult, as the subject advances, to resist indefinitely the need for a somewhat more systematic nomenclature for purely chemical designations, however appropriate it may be to retain the older names in general nutritional and biochemical contexts.

Wald (1935) chose the name retinene because he regarded the compound as a carotenoid, but when it was identified as vitamin $\mathbf{A}$ aldehyde (Morton \& Goodwin, 1944) the suggestion was made that 'retinaldehyde' or 'retinal' would be more suitable. Logically, vitamin A alcohol would be retinol; vitamin $A_{2}$, 3-dehydroretinol; and retinene $e_{2}$, 3-dehydroretinal.

The problem of nomenclature is brought to a head with the case of a Schiff's base made from

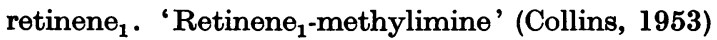
is obviously only a temporary expedient. The minimum departure from current practice would be to use retinal for retinene $e_{1}$. On this basis the Schiff's base becomes retinylidenemethylamine and indicator yellow analogues retinylideneamines. Natural indicator yellow 1 would be $N$-retinylideneopsin, and acid indicator yellow would be a salt of the ammonium form of retinylidene-opsin. Simi-

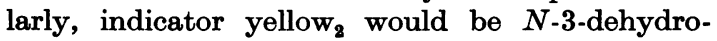
retinylidene-opsin. A refinement of this nomenclature to distinguish between different forms of indicator yellow is suggested by Morton \& Pitt (1955).

This usage is serviceable in the present context and goes far to meet the objections of Wald (1953) to the trivial names (such as indicator yellow) now in use for visual pigments. 


\section{Antimony trichloride colour reactions}

There is no certainty concerning the precise structure of the chromogens produced by the addition to polyene compounds of an antimony trichloride solution, and there is evidence that antimony trichloride itself is not the active substance (Brüggeman, Krauss \& Tiews, 1952). It is, however, generally agreed that the chromogens are ionized forms of the polyenes (Meunier, 1942).

Those recorded in this paper as derived from retinylidenemethylamine, retinylidenedimethylammonium iodide, and retinene oxime differ markedly from those given by other vitamin A derivatives but resemble one another closely. It seems probable that all three Carr-Price chromogens are of similar type. The coloured compound formed by retinylidenemethylamine in concentrated sulphuric acid bears a superficial resemblance to them.

Whatever the nature of these coloured compounds may be, it is obvious that the introduction of an azomethine grouping into a polyene has a very great influence on the manner in which the molecule can ionize.

\section{Artificial chromogens and rhodopsin}

The cardinal difficulty in approaching the structure of rhodopsin is to account for the displacement of $\lambda_{\max }$ of retinene from 385 to $500 \mathrm{~m} \mu$. on uniting with the protein opsin. In the past, attempts have been made to overcome this by postulating that two conjugated molecules of retinene were involved, but Hubbard (1954) has shown that the chromophore of rhodopsin contains only one molecule of retinene.

It has been suggested (e.g. Wald, 1948) that the rhodopsin chromophore is some ionized form of retinene, but how this could be formulated so as to account for the absorption band with a maximum at $500 \mathrm{~m} \mu$. has remained puzzling. The antimony trichloride and sulphuric acid colour reactions reported here with retinylideneamine derivatives are the nearest approach to reproducing the chromophore. They have maxima near $500 \mathrm{~m} \mu$. and, in the case of Carr-Price chromogens, they give broad absorption curves similar to that of rhodopsin: the half-bandwidth of rhodopsin is $100 \mathrm{~m} \mu$. (Collins, Love \& Morton, 1952), of retinylidenemethylamine and antimony trichloride about $110 \mathrm{~m} \mu$. (As the sulphuric acid colour produced was unstable, its bandwidth was not determined.) These chromogens have molecular extinction coefficients of the same order as that of the rhodopsin chromophore, and they are formed from retinylideneamino compounds which are known to be produced in the retina from the carbon-nitrogen linkage present in rhodopsin (Collins, 1953). Further, although most derivatives of vitamin A when ionized give coloured products with $\lambda_{\max }$ at wavelengths near or above $600 \mathrm{~m} \mu$., retinylideneamine derivatives cannot be induced, even in strongly ionizing media, to give absorption peaks at wavelengths much longer than $500 \mathrm{~m} \mu$.

These artificial chromogens are not, however, photosensitive, and their production under such grossly unphysiological conditions may have no relevance to the changes undergone by retinene on uniting with opsin in the eye. Nevertheless, this work brings out potentialities of retinylideneamino compounds which deserve consideration in future investigations on the structure of rhodopsin.

It will be noticed (Fig. 3) that both the retinylideneammonium salts in chloroform solution show a marked inflexion around $350-380 \mathrm{~m} \mu$., and that rhodopsin also shows a small peak ( $\beta$-band) in this region. The rhodopsin band may be a cis-peak (Hubbard \& Wald, 1952), but it is interesting that an inflexion is found here associated with an apparently all-trans-retinylideneammonium chromophore.

\section{SUMMARY}

1. A crystalline compound showing the spectroscopic characteristics of indicator yellow has been prepared from retinene and methylamine.

2. Analytical results show this to be a Schiff's base, to which the trivial name of retinylidenemethylamine has been given. (The $\mathrm{C}_{19} \mathrm{H}_{27} \mathrm{CH}=$ radical has been named retinylidene-this nomenclature is discussed.)

3. The spectroscopic properties and antimony trichloride colour reactions of retinene oxime are reported, and confirm the Schiff's base structure of the indicator yellow analogue.

4. Corresponding Schiff's bases have been prepared in solution from methylamine and other aldehydes and show similar shifts of $\lambda_{\max }$ in acid.

5. Retinylidenemethylamine reacts with methyl iodide to give retinylidenedimethylammonium iodide, which has $\lambda_{\max }$ (chloroform) $485 \mathrm{~m} \mu$.

6. These results show that the bathochromic shift of retinylidenemethylamine in acid is due to the formation of a retinylideneammonium salt.

7. Indicator yellow derived directly from rhodopsin is therefore $N$-retinylidene-opsin and 'acid indicator yellow' the corresponding ammonium salt.

8. Unusual chromogens are produced from retinylideneamino compounds by the action of antimony trichloride and concentrated sulphuric acid. Their resemblance to the rhodopsin chromophore is discussed.

We are indebted to the Medical Research Council for financial assistance, including a studentship to P.S.

F.D.C. was the holder of an Imperial Chemical Industries Fellowship. 


\section{REFERENCES}

Ball, S., Collins, F. D., Dalvi, P. D. \& Morton, R. A. (1949). Biochem. J. 45, 304.

Ball, S., Goodwin, T. W.\& Morton, R.A. (1948). Biochem.J. 42, 516.

Ball, S. \& Morton, R. A. (1949). Biochem. J. 45, 298.

Barany, H. C., Braude, E. A. \& Pianka, M. (1949). J. chem. Soc. p. 1898.

Brüggeman, J., Krauss, W. \& Tiews, J. (1952). Chem. Ber. 85, 315.

Cama, H. R., Collins, F. D. \& Morton, R. A. (1951). Biochem. J. 50, 48.

Collins, F. D. (1953). Nature, Lond., 171, 469.

Collins, F. D., Green, J. N. \& Morton, R. A. (1954). Bioch. J. 56, 493.

Collins, F. D., Love, R. M. \& Morton, R. A. (1952). Biochem. J. 51, 292.

Collins, F. D. \& Morton, R. A. (1950). Biochem. J. 47, 10.
Decker, H. \& Becker, P. (1913). Liebigs Ann. 295, 362.

Dewar, M. J. S. (1949). The Electronic Theory of Organic Chemistry, chap. 15. Oxford: Clarendon Press.

Farrar, K. R., Hamlet, J. C., Henbest, H. B. \& Jones, E. R. H. (1952). J. chem. Soc. p. 2657.

Hausser, K. W., Kuhn, R., Smakula, A. \& Hoffer, M. (1935). Z. phys. Chem. B 29, 371.

Hubbard, R. (1954). J. gen. Physiol. 37, 381.

Hubbard, R., Gregerman, R. I. \& Wald, G. (1953). J. gen. Physiol. 36, 415.

Hubbard, R. \& Wald, G. (1952). J. gen. Physiol. 36, 269.

Lythgoe, R. J. (1937). J. Physiol. 89, 331.

Meunier, P. (1942). C.R. Acad. Sci., Paris, 215, 470.

Morton, R. A. \& Goodwin, T. W. (1944). Nature, Lond., $153,405$.

Morton, R. A. \& Pitt, G. A. J. (1955). Biochem. J. 59, 128.

Wald, G. (1935). J. gen. Physiol. 19, 351.

Wald, G. (1948). J. gen. Physiol. 31, 489.

Wald, G. (1953). Annu. Rev. Biochem. 22, 497.

Wald, G. \& Brown, P. K. (1953). J. gen. Physiol. 37, 189.

\title{
Studies on Rhodopsin
}

\section{9. pH AND THE HYDROLYSIS OF INDICATOR YELLOW}

\author{
By R. A. MORTON ANd G. A. J. PITT \\ Department of Biochemistry, The University of Liverpool
}

(Received 16 June 1954)

Lythgoe (1937) showed that on exposure to light, rhodopsin (visual purple) solutions break down to give the pigment 'indicator yellow', which has $\lambda_{\max .}$ about $365 \mathrm{~m} \mu$. in alkali ('alkaline' indicator yellow) and about $440 \mathrm{~m} \mu$. in acid ('acid' indicator yellow) (Collins \& Morton, 1950).

The $\mathrm{pH}$ affects not only the spectrum but also the stability of indicator yellow. Lythgoe (1937) found his preparations to be stable above $\mathrm{pH} 7$ in the alkaline form and fairly stable in the acid form at pH 3.3. Between $\mathrm{pH} 4 \cdot 0$ and 6.1, however, the acid form decomposed to give what Bliss (1948) later identified as retinene (vitamin $\mathbf{A}$ aldehyde). To explain this behaviour Lythgoe postulated two forms of acid indicator yellow-one stable (existing at $\mathrm{pH} 3 \cdot 3$ ), the other unstable (existing between pH 4.0 and 6.1). Wald (1938), Bliss (1948) and Collins \& Morton (1950) have reported acid indicator yellow as unstable, but they all studied indicator yellow solutions near $\mathrm{pH} 4 \cdot 0$, i.e. they were dealing with the unstable form. Lythgoe's stable acid indicator yellow has largely been overlooked.

Substances behaving spectroscopically as indicator yellow, and known as indicator yellow analogues, have been made by the interaction of retinene and amines (Ball, Collins, Dalvi \& Morton, 1949). These are Schiff's bases-retinylideneamines-which in acid solution form retinylidene- ammonium salts (using the nomenclature of Pitt, Collins, Morton \& Stok, 1955). It has been observed in this laboratory (F.D.Collins, unpublished) that, in fairly strongly acid solutions, these indicator yellow analogues are stable, in the sense that they do not hydrolyse to retinene. The availability of retinylidenemethylamine (a crystalline indicator yellow analogue; Pitt et al. 1955) allows its stability to be studied in aqueous solution without interference caused by other substances inevitably present in solutions of natural indicator yellow obtained from eyes.

Such a study is reported in this paper and, based on the knowledge thus obtained, further investigations have been carried out of the relationship between indicator yellow and rhodopsin.

\section{EXPERIMENTAL}

Absorption spectra were determined by means of a photoelectric spectrophotometer.

Retinylidenemethylamine. This was prepared by the method of Pitt et al. (1955). The crystalline material was used.

Aqueous solutions of retinylidenemethylamine. These were made using Tween 80 (polyoxyethylene derivative of sorbitan mono-oleate, Honeywill and Stein, Ltd., St James' Square, London, S.W. 1) by the technique of Bliss (1951) and were of concentrations suitable for reading in the spectrophotometer (approx. $\mathrm{M} \times 10^{-5}$ ). 